\title{
Impact of COVID-19 on Healthcare Workers
}

Bhavin Sonani MD ${ }^{1}$, Pankaj Bansal MD²*, Austin Cusick MS-IV³, Amandeep Goyal MD ${ }^{4}$

${ }^{1}$ HSHS St John's Hospital. 800 E Carpenter St, Springfield, IL 62769.

${ }^{2}$ Mayo Clinic Health System. 1400 Bellinger Street, Eau Claire, WI - 54701. Phone: 773-899-4590, ORCID ID 0000-0001-6315-6879

${ }^{3}$ Ohio University Heritage College of Osteopathic Medicine. 35 W Green Dr, Athens, OH 45701.

${ }^{4}$ University of Kansas Medical Center. 3901 Rainbow Blvd, Kansas City, KS 66160. Phone: 740-434-8258, ORCID ID 0000-0001-6070-1747

*Corresponding Author: Pankaj Bansal, Mayo Clinic Health System. 1400 Bellinger Street, Eau Claire, WI - 54701.Phone: 773-899-4590, ORCID ID: 0000-0001-6315-6879.

Received date: August 18, 2020; Accepted date: September 04, 2020; Published date: September 07, 2020

Citation: B Sonani, P Bansal, A Cusick, A Goyal. (2020) Impact of COVID-19 on Healthcare Workers. International Journal of Clinical Case Reports and Reviews. 3(3); DOI: 10.31579/2690-4861/047

Copyright: (C) 2020 Pankaj Bansal, This is an open-access article distributed under the terms of the Creative Commons Attribution License, which permits unrestricted use, distribution, and reproduction in any medium, provided the original author and source are credited.

\begin{abstract}
Since its origin in the Wuhan province in China in December 2019, the novel severe acute respiratory syndrome coronavirus 2 (SARS-Cov-2) has impacted 213 countries and as of August 8, 2020, there have been 19,187,943 cases and 716,075 deaths due to the coronavirus disease 2019 (COVID-19) worldwide. In the United States alone, there have been more than 160,000 deaths due to COVID-19. The pandemic has impacted people of all age groups, socioeconomic status, and industrial sectors, although the healthcare workers, who are on the frontlines, have been particularly impacted hard.
\end{abstract}

Keywords: covid-19; healthcare workers

\section{Introduction}

Since its origin in the Wuhan province in China in December 2019, the novel severe acute respiratory syndrome coronavirus 2 (SARS-Cov-2) has impacted 213 countries and as of August 8, 2020, there have been $19,187,943$ cases and 716,075 deaths due to the coronavirus disease 2019 (COVID-19) worldwide [1]. In the United States alone, there have been more than 160,000 deaths due to COVID-19 [2]. The pandemic has impacted people of all age groups, socioeconomic status, and industrial sectors, although the healthcare workers, who are on the frontlines, have been particularly impacted hard. Healthcare workers are defined as anyone engaged in actions whose primary intent is to enhance health and include not only the health service providers such as physicians, nurses, and technicians, but also others including health management support staff such as administrators, clerical workers, accountants, craft and trade workers, etc [3]. They serve as the first wall of defense against the pandemic; however, the pandemic has led to significant emotional, mental, physical, and financial strain on healthcare workers.

\section{Risk of infection}

Healthcare workers, especially the health service providers are at the highest risk of getting infected due to their direct exposure to the COVID19 virus while providing care to the sickest patients. As of August $10^{\text {th }}$, There were 128,933 infections and more than 600 deaths among healthcare workers due to COVID 19 infection. ${ }^{2}$ Despite this risk, healthcare workers across the globe have shown admirable courage without taking a step back in providing care to patients with COVID-19. As with the general population, several healthcare workers have underlying health conditions and belong to the "high-risk" category for severe COVID-19 infection compared to others. While some work sectors may have the option of "work-from-home" to decrease the risk of exposure in the high-risk workers, health service providers rarely have such luxury. Telemedicine is still an evolving science that is still not widely available and may not be an appropriate substitute for direct or face-to-face patient contact in all encounters, especially those involving management of patients in intensive and critical care units. Further, there is a global shortage of healthcare workers, and often it is not possible to find a replacement for them.

Personal protective equipment (PPE) such as face masks, surgical masks, N95 respirator masks, gowns, and eye protection have been recommended by the Centers for Disease Control (CDC) with guidance for appropriate use in healthcare workers in order to prevent infection [4]. However, the demand for PPE has risen several-fold with the rapid spread of COVID19 , leading to a nation-wide shortage of PPE. To conserve the available PPE, healthcare workers have had to resort to practices such as reusing the same PPE for several days. Several health facilities have had to establish procedures to recycle and reuse the PPE.

Regardless of underlying health conditions and a shortage of PPE, healthcare workers have continued to provide direct care to patients with COVID-19, while risking themselves from getting infected. Better availability of telemedicine shall be encouraged to be used in appropriate circumstances, which could help to prevent the avoidable risk of exposure in health service providers. Production of PPE shall be escalated to overcome shortages in areas hardest hit by the COVID-19.

\section{Emotional and mental stress}

Healthcare workers are at significant risk of mental and emotional stress due to several reasons including long working hours, separation from family, and a higher risk of infection. Several studies have shown an increased prevalence of depression, anxiety, burnout, insomnia in 
healthcare providers since the onset of the pandemic [5-7]. The risk has been especially higher amongst women, healthcare workers who have been infected, and those living in areas with higher incidence rates of the infection $[7,8]$.

Besides the risk of getting infected themselves, healthcare workers face the additional risk of spreading the infection to their family members. This stress is significantly higher in those with family members in the highrisk category such as elderly and/or immunocompromised family members. To decrease this risk, several healthcare workers have to selfisolate while they continue to provide care to those infected with COVID19. Further, if infected, healthcare workers have to self-quarantine for several days. If hospitalized due to the infection, they are isolated from their family, while in constant fear of the outcomes, especially given the lack of a definite therapeutic option so far. This family separation in addition to the long work hours can cause mental and physical exhaustion. COVID-19 carries a high mortality in hospitalized patients, and to mitigate the risk of infection, most healthcare facilities do not allow visitors and family members to visit the patients. At times, healthcare workers are the only ones present alongside a patient dying of the COVID-19, leading to a feeling of helplessness and despair, especially with the rising number of deaths. Rates of post-traumatic stress disorder (PTSD) and burnout were already high amongst the healthcare workers, and COVID-19 has furthered this concern [9]. Suicide rates are higher in physicians than in general populations and have been reported in physicians providing care to patients infected with COVID-19 owing to this added stress $[10,11]$. Those with underlying mental illnesses such as depression are at a higher risk of developing anxiety and depression symptoms due to this stress [8].

The mental health of the caregivers needs to be tended to, and several hospitals have established virtual support sessions and 24/7 helplines to help overcome and prevent burnout and stress in the healthcare workers [12]. As with the rest of the population, the healthcare workers are not prompt in seeking help during or even after developing mental and emotional stress. Studies have shown that providing healthcare workers with adequate break times, recognition of their work by their administration, and implementing strict infection control guidelines have a positive impact on their psychological support and benefit [13]. Symptoms of PTSD and depression may last for several months to years, and those with adverse psychological effects of the pandemics shall be provided with long-term support.

\section{Financial strain}

The Healthcare industry has suffered major financial losses due to mitigation guidelines implemented to reduce transmission of COVID 19 infection and to ensure equipment and hospital capacity. To offset these financial losses, several healthcare workers were either furloughed or lost their employment. The Healthcare industry lost close to 1.4 million jobs in April 2020 according to the Bureau of Labor Statistics [14]. Although the unemployment rate is improving since April 2020, it is still not at the level it was in February 2020. In July 2020, 126,000 jobs were added to the healthcare sector, however, overall employment in healthcare is still down by 797,000 compared to February 2020 level [15]. Loss of employment leads to loss of health insurance in several individuals, thus impacting their ability to seek medical care in case of emergencies as well as routine care. Further, several healthcare systems announced a reduction in salary and productivity bonuses for healthcare workers [16]. A decline in routine and elective procedures led to a loss of revenue for physicians and hospitals. These financial losses have threatened the sustainability of several hospitals and medical offices. Rural and primary-care practices have been especially more vulnerable [17]. Lastly, healthcare workers who are continuing to provide care to patients with COVID-19 often have to work for extended hours. In addition to a reduction in incomes, they have had to face secondary additional expenses such as finding additional resources for childcare.

The government has taken several measures as an attempt to offset some of these losses. State and Federal level financial aid has been provided to hospitals and physicians who endured financial losses due to the decline in elective procedures and to those who suffered unemployment due to the pandemic [18]. The Center for Medicare \& Medicaid Services (CMS) approved telemedicine reimbursements for phone and video visits [19]. However, these efforts may not suffice long-term, especially as the virus continues its spread.

\section{Immigration and visa uncertainties}

Almost $25 \%$ of all practicing specialists in the United States are international medical graduates, many of whom are on non-immigrant visas such as H1-B and J1 [20, 21]. Healthcare workers on non-immigrant visas face a unique uncertainty during the current unprecedented times [22]. If these workers become disabled, lose their employment, or die while taking care of patients with COVID-19, they lose their visa status and are not eligible for long-term disability. Further, loss of visa status of the primary visa holder in the family leads to loss of immigration status for their spouse and children leaving them with no choice other than leaving the country. These concerns have furthered the stress in the immigrant healthcare worker community.

The United States Congress has introduced several bills trying to address these concerns. ${ }^{23,24}$ Time is of the essence, and although encouraging, these steps need urgent attention of the elected officials and representatives in order to support the immigrant physicians, who are indispensable in the current unprecedented times.

\section{Conclusion}

COVID-19 poses serious and multifaceted impacts on the healthcare workers, including their physical well-being, emotional and mental health, and financial status. Immigrant healthcare workers further face fears of visa and immigration uncertainties. Immediate actions by the healthcare facilities and government agencies are needed to address these concerns, to keep this frontline workforce intact so that they can continue to fight the battle against this pandemic.

\section{Author contributions}

All authors have made substantial contributions to the creation of this manuscript including writing the initial manuscript, literature review, and reviewing, and revising the final version. The final manuscript has been reviewed and approved by all authors.

\section{Financial disclosure and conflict of interest statement}

We confirm that the authors have no financial disclosures, competing interests, and conflict of interest. The study has not received any financial support or other benefits from commercial sources for the work reported on in the manuscript. The manuscript represents the original work of the authors and identical or similar work has not been published or submitted for publication elsewhere.

\section{Data sharing statement}

There is no data in this work. 


\section{References}

1.World Health Organization, Coronavirus disease (COVID-2019) situation reports. Accessed August 9, 2020.

2.Centers for Disease Control and Prevention. Coronavirus Disease 2019 (COVID-19). Cases in the U.S. Accessed August 10, 2020.

3.3World Health Organization, The World Health Report 2006 accessed. Accessed August 10, 2020.

4.4Centers for Disease Control and Prevention. Information for healthcare professionals about Coronavirus (COVID-19). Accessed August 9, 2020.

5.Braquehais MD, Vargas-Cáceres S, Gómez-Durán E, et al. (2020) The impact of the COVID-19 pandemic on the mental health of healthcare professionals. QJM: An International Journal of Medicine.

6.Chew NWS, Lee GKH, Tan BYQ, et al. (2020) A multinational, multicentre study on the psychological outcomes and associated physical symptoms amongst healthcare workers during COVID-19 outbreak. Brain, Behavior, and Immunity. 88:559565.

7.Lai J, Ma S, Wang Y, et al. (2020) Factors Associated With Mental Health Outcomes Among Health Care Workers Exposed to Coronavirus Disease 2019. JAMA Netw Open. 3(3):e203976.

8. Bettinsoli ML, Di Riso D, Napier J, et al. (2020) Psychological Impact and Contextual Factors Associated With Physical and Mental Health Conditions of Italian Healthcare Professionals During the Covid-19 Disease Outbreak.

9.Kang L, Ma S, Chen M, et al. (2020) Impact on mental health and perceptions of psychological care among medical and nursing staff in Wuhan during the 2019 novel coronavirus disease outbreak: A cross-sectional study. Brain, Behavior, and Immunity. 87:11-17.

10. 'I couldn't do anything': The Virus and an E.R. Doctor's Suicide. Accessed August 11, 2020.
11. Dutheil F, Aubert C, Pereira B, et al. (2019) Suicide among physicians and health-care workers: A systematic review and meta-analysis. PLoS ONE. 14(12):e0226361.

12. Rimmer A, Chatfield C. (2020) what organisations around the world are doing to help improve doctors' wellbeing? BMJ.

13. Cai H, Tu B, Ma J, et al. (2020) Psychological Impact and Coping Strategies of Frontline Medical Staff in Hunan Between January and March 2020 During the Outbreak of Coronavirus Disease 2019 (COVID-19) in Hubei, China. Med Sci Monit.

14. Bureau of Labor Statistics, U.S. Department of Labor, The employment situation April 2020. Accessed August 9, 2020.

15. Bureau of Labor Statistics, U.S. Department of Labor, The employment situation July 2020. Accessed August 9, 2020.

16. Bureau of Labor Statistics, U.S. Department of Labor, The employment situation June 2020. Accessed August 9, 2020.

17. Covid-19 and the Upcoming Financial Crisis in Health Care. Accessed August 11, 2020.

18. Congress.gov H.R. 748-CARES Act. Accessed August 9, 2020.

19. Centers for Medicare and Medicaid services. Medicare telemedicine healthcare provider fact sheet. Accessed August 9, 2020.

20. Association of American Medical Colleges. Active Physicians Who Are International Medical Graduates (IMGs) by Specialty, 2017. Accessed August 9, 2020.

21. American Medical Association. Immigration information for international medical graduates. Accessed August 9, 2020.

22. Tiwari V, Bhardwaj A, Sonani B, Mehta AC. Urgent Issues Facing Immigrant Physicians in the United States in the COVID-19 Era. Annals of Internal Medicine. Published online July 2, 2020:M20-4103.

23. Congress.gov. S.3599 - Healthcare Workforce Resilience Act. Accessed August 9, 2020.

24. Congress.gov. S.948 - Conrad State 30 and Physician Access Reauthorization Act. Accessed August 9, 2020.
This work is licensed under Creative Commons Attribution 4.0 License

To Submit Your Article Click Here: Submit Article

DOI: $10.31579 / 2690-4861 / 047$
Ready to submit your research? Choose Auctores and benefit from:

* fast, convenient online submission

* rigorous peer review by experienced research in your field

* rapid publication on acceptance

* authors retain copyrights

* unique DOI for all articles

* immediate, unrestricted online access

At Auctores, research is always in progress.

Learn more www.auctoresonline.org/journals/international-journal-ofclinical-case-reports-and-reviews 